\title{
Knowledge and Awareness about Contraception among Married Females under Age Group 20 to 35 Years in Rural Area of Sawangi (Meghe), Wardha
}

\author{
Amrita Sinha, Neharika Malhotra, SA Inamdar
}

\section{ABSTRACT}

Objectives: The aims of the study are:

1. To bridge the gap of knowledge regarding contraception.

2. To enhance the awareness regarding contraception for spacing for a better outcome.

3. To reduce contraceptive related problems, incidence of unwanted pregnancy and pregnancy-related risk in future.

4. To assess the acceptance of different modes of contraception.

5. To find out the success of contraceptive practice which lies in the acceptance of a regular contraceptives to prevent future pregnancies.

Materials and methods: It is a qualitative and quantitative descriptive method to assess married females about knowledge of contraception and other areas of reproductive health. Questionnaire will be used to assess the knowledge of 300 married females ranging in age from 20 to 35 years in rural area Sawangi (Meghe) in Wardha district.

Results: Most of the respondents used MTP and sterilization (48\%), followed by barrier (23\%), IUCD (17\%), oral contraception $(10 \%)$. Their spouses were engaged in skilled as well as unskilled work. Respondents were being married for less than 5 years $(37 \%), 36 \%$ had a married life span of 5 to 10 years. Literacy rate of contraceptive users were not that much high, $31 \%$ had primary schooling followed by $25 \%$ had secondary schooling.

Majority of them (60\%) were in age group 26 to 30 years, followed by $25 \%$ in age group 31 to 35 years.

Conclusion: This study was done to evaluate the awareness and the use of different mode of contraception in age group 20 to 35 years. This study is mainly focuses on rural hospital to avoid unseen complications of unwanted termination of pregnancy. The awareness of women regarding the various contraceptive methods was high for MTP and sterilization (48\%), followed by barrier method (23\%). The commonest reason quoted by the women for not using a contraceptive method was the unwillingness of husband. Along with the women, their spouses should be counseled and educated so that awareness spreads to a greater extent.

Keywords: Knowledge, Practice and perceptions of contraception.

How to cite this article: Sinha A, Malhotra N, Inamdar SA. Knowledge and Awareness about Contraception among Married Females under Age Group 20 to 35 Years in Rural Area of Sawangi (Meghe), Wardha. J South Asian Feder Obst Gynae 2012;4(1):43-46.

\section{Source of support: Nil}

Conflict of interest: None declared

\section{INTRODUCTION}

Improving reproductive health is central to achieving the millennium development goals on improving maternal health, reducing child mortality and eradicating extreme poverty. ${ }^{1,2}$ This requires that women have access to safe and effective methods of fertility control. The promotion of family planning, so that women can avoid unwanted pregnancy, is central to the World Health Organisation (WHO) work on improving maternal health and is core to achieving the millennium development goal on this. ${ }^{3}$ A variety of different methods of contraception are available, which are generally extremely safe compared with the risks associated with pregnancy and childbirth. Not all methods are suitable for everyone. Expanding the number of family planning options available to women is a critical part of increasing contraceptive coverage, decreasing unintended pregnancies and reducing maternal morbidity and mortality around the globe. ${ }^{4,5}$ More than 200 million women in developing countries do not have access to effective contraception, even while family planning (FP) is one of the most cost-effective ways to reduce maternal, infant and child mortality. ${ }^{1}$ It is estimated that family planning could prevent as many as one in every three maternal deaths and one in every 11 child deaths, by allowing women to delay motherhood, space births, avoid unintended pregnancies and abortions, and stop childbearing when they have reached their desired family size. ${ }^{6}$ Family planning also enhances social development by alleviating poverty; improving the environment, agriculture, water and sanitation; and increasing access to primary education. Through these many corollary benefits, family planning programs are essential to achieving development targets, including the millennium development goals (MDGs). ${ }^{7,9}$

Previously identified limits to contraceptive use among adolescents in developing countries include lack of knowledge, sex education and access to services; risk misperceptions; negative social norms around premarital sexual activity and pregnancy. ${ }^{11,12}$ The decision to use one contraceptive method over another is influenced by personal choice, perceptions of efficacy, personal risk, access, age, cost, gender, education, ethnicity, marital status, current number of children, sexual orientation, pattern of sexual activity and level of cooperation between partners. ${ }^{10,13,14}$

Keeping in mind all the present knowledge and problem associated with use of contraception, study has been carried out to see the rate of awareness in married females. This will help to reduce the rate of complications associated with contraceptive methods and other reproductive problems.

\section{HISTORICAL PERSPECTIVE}

History has demonstrated that for centuries, women and men have been using various methods of contraception, some of 
which were pernicious to women's overall health, to prevent pregnancy and control their fertility. ${ }^{1}$ In Canada, by the late 1800 s many forms of contraception were being used, including abstinence, vaginal sponges, diaphragms, condoms, withdrawal, douching, prolonged breastfeeding, rhythm method, sterilization and abortion. These methods, now greatly improved, continue to be used. From the late 1860 s to the 1930 s, a significant amount of controversy, conflicting theories and social stigma were associated with contraception usage. Many women were discouraged from seeking information from physicians, who were often reluctant to provide information about contraception. ${ }^{2}$ By the 1960 s, there was a greater acceptance of contraception, evidenced by legislative changes in 1969, that legalized birth control. In the developed world, combined oral contraceptives (COCs) remain a popular choice for women.

Data from randomly selected European women aged 15 to 49 years in 2006, showed the highest usage rates in France (49\%) and the Czech Republic (44\%) with the lowest use in Russia, the Baltic States and Spain (15-18\%). ${ }^{1}$ In 2006 to 2008, $17 \%$ of women aged 15 to 44 years in the United States who reported that they were using contraception taking OCs, and $34 \%$ of a representative survey of Australian women aged 16 to 59 years, using contraception in 2001 , reported using this method of contraception. ${ }^{15,16}$ With the advent of oral contraceptive pill, improved accessibility to other forms of contraception, and later the risk of HIV or AIDS, societies view of contraception has evolved and continue to do so.

\section{OBJECTIVES OF THE STUDY}

The aims of the study are:

1. To bridge the gap of knowledge regarding contraception.

2. To enhance the awareness regarding contraception for spacing for a better outcome.

3. To reduce contraceptive related problems, incidence of unwanted pregnancy and pregnancy-related risk in future.

4. To assess the acceptance of different modes of contraception.

5. To find out the success of contraceptive practice which lies in the acceptance of a regular contraceptives to prevent future pregnancies.

\section{MATERIALS AND METHODS}

\section{Study Design}

It is a prospective study between December 2009 to July 2010. A study was carried out at Acharya Vinoba Bhave Rural Hospital, Sawangi (Meghe), Wardha. This was a hospital-based clinical study. The sample size of 300 married women was selected attending the obstetrics and gynecology OPD after fulfilling the selection criteria. The data was recorded using a questionnaire administered to them. Ethical committee approval was obtained, a questionnaire was framed and knowledge regarding contraception awareness and practices were ascertained. Interview was conducted to all the women between 20 and 35 years age group, using any mode of contraception, the questionnaire contained questions dealing with socioeconomic characters, women's spouse, their employment, marital status, the number of childrens, the reason for which they sought the service, concurrent contraceptive method used, knowledge and awareness about different mode of contraception.

\section{Sample Size}

This study was performed on 300 married women in duration between December 2009 to July 2010.

\section{Inclusion Criteria}

- Married females between 20 and 35 years of age

- Willing to have knowledge regarding contraceptions

- Desire for spacing children in future

- Women with history of induced abortions.

\section{Exclusion Criteria}

- History of infertility

- Women not in reproductive age group

- Women with associated medical disorders

- Who have adopted permanent method of sterilization.

\section{RESULTS}

In Figure 1, the most commonly used method for family size limitation was found as tubectomy along with MTP. It is evident that $48 \%$ women opted permanent sterilization followed by barrier method (23\%). The percentage of IUCD and OCP users were 17 and $10 \%$. Women who opted for injectable contraception were minimal $(2 \%)$. Figure 2 shows the educational status of women using contraceptive method, literacy rate of contraceptive users were not that high. Thirtyone percent had primary schooling followed by $25 \%$ who had secondary schooling. Seventeen percent were illiterate, $15 \%$ graduate and $11 \%$ postgraduate. Figure 3 shows the distribution of women according to the religion, $66 \%$ contraceptive users were Hindu, rest followed by Christian, Muslims and others women having two children were more susceptible to accept contraceptive advice (Fig. 4). Figure 5 shows distribution of respondents according to age. Sixty percent of women were in age group 26 to 30 years, $25 \%$ were in age group 31 to 35 years, and $15 \%$ were in age grope 20 to 25 years, $60 \%$ of women got married at age $<23$ years, $25 \%$ were married between 24 to 29 years, and $15 \%$ got married at $\geq 35$ years (Figs 6 and 7). Forty percent of women belong to working class and $60 \%$ were housewife. Figure 8 highlights the reason for nonuse of contraception, $64 \%$ has nonavailability, $27 \%$ had nonwillingness of husband and $9 \%$ had social/family pressure to prove fertility.

\section{DISCUSSION}

This study was done to evaluate the awareness and use of different mode of contraception in age group 20 to 35 years. 


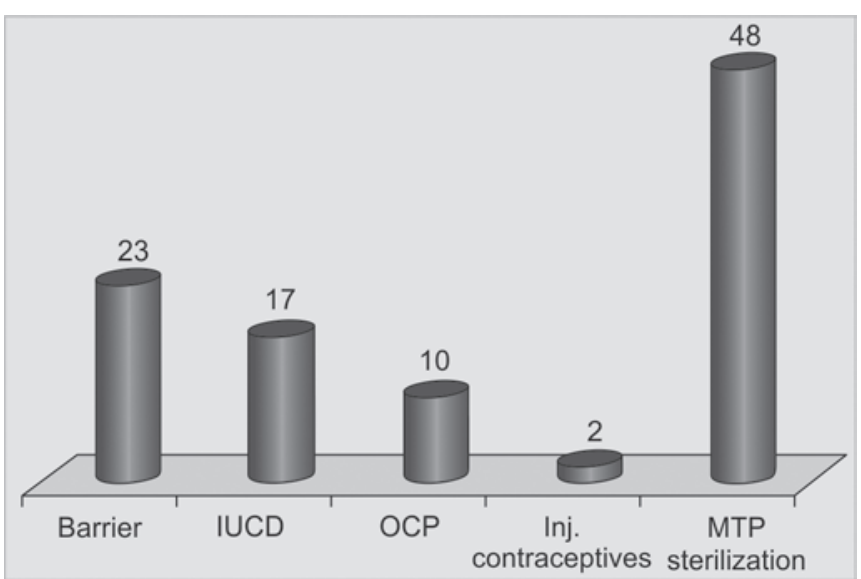

Fig. 1: Distribution of women according to mode of contraception use

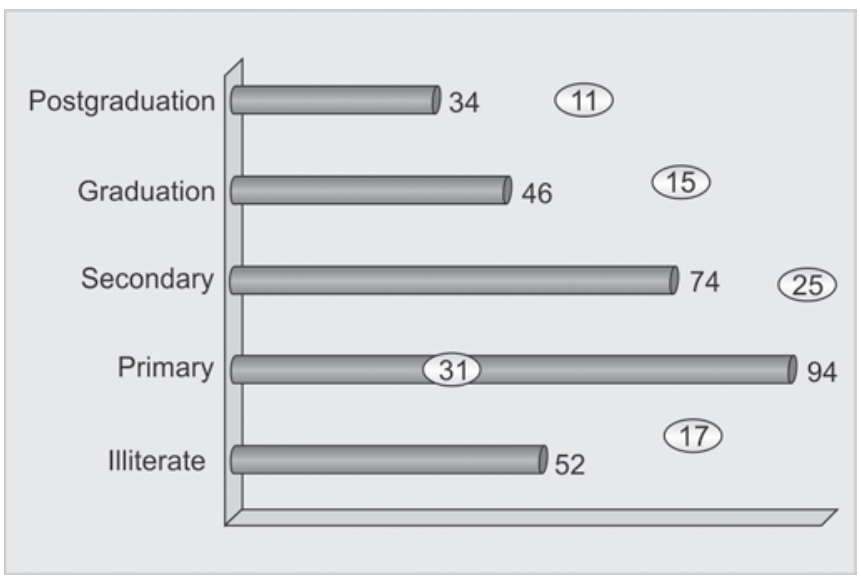

Fig. 2: Distribution according to educational status of women (most of the patients received education up to primary standard only, followed by secondary schooling)

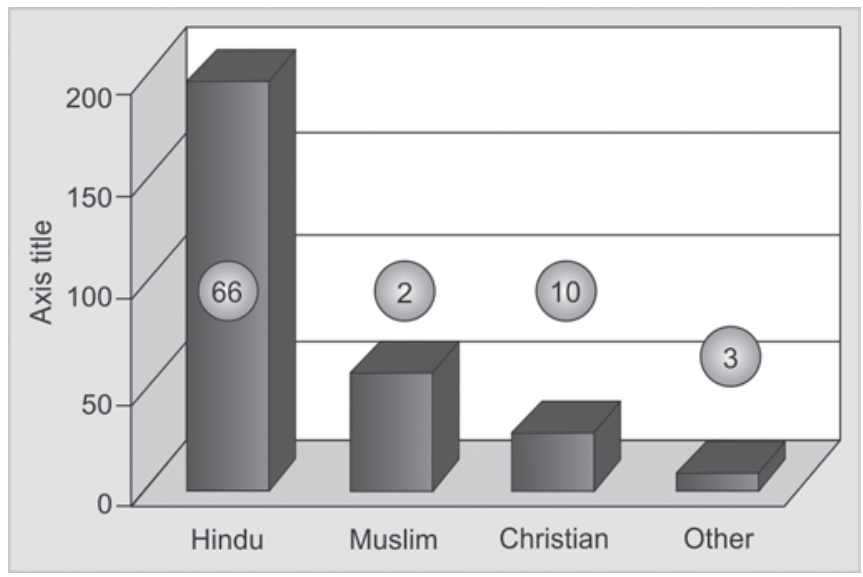

Fig. 3: Distribution of women according to their religion

This study is mainly focuses on rural hospital to avoid unseen complications of unwanted termination of pregnancy. Most of the respondents were aware of permanent methods followed by temporary methods mainly barrier, IUCD and oral contraceptives. Myths, literacy, lack of proper knowledge of application, and low socioeconomic status were the leading factors for not using the methods. They were not willing to use

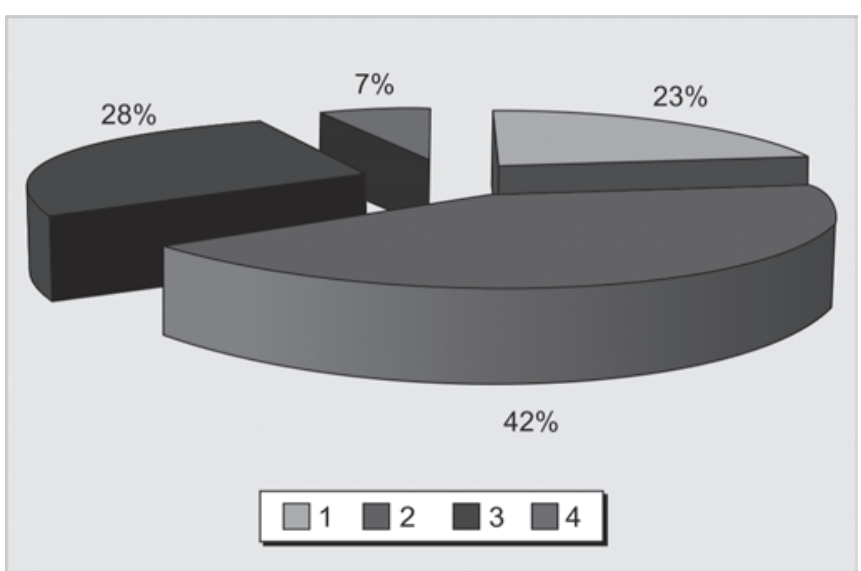

Fig. 4: Distribution of women as per the gravida status

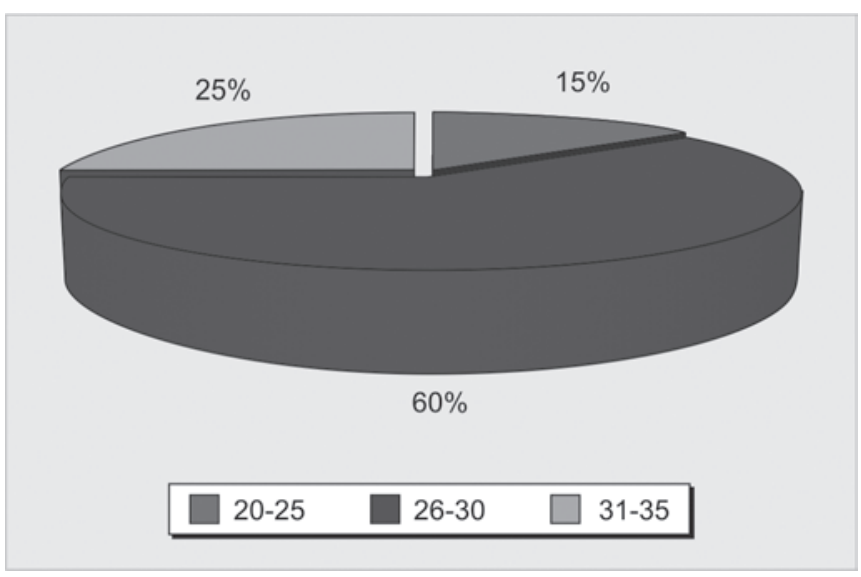

Fig. 5: Distribution of respondents according to age

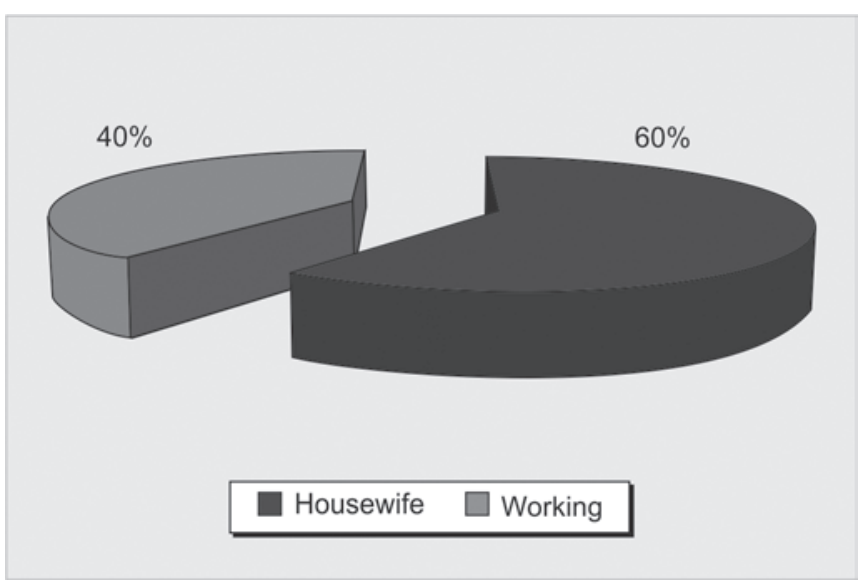

Fig. 6: Distribution of women according to their occupation

injectable form due to misconception, such as it affects heart and their fertility. Proper education of every women is must. Some of the women though having completed the family size did not undergo sterilization or use any other contraceptive as it was against their belief. Another women with four children preferred to use herbal medicines and felt uncomfortable to use modern contraceptive method. 


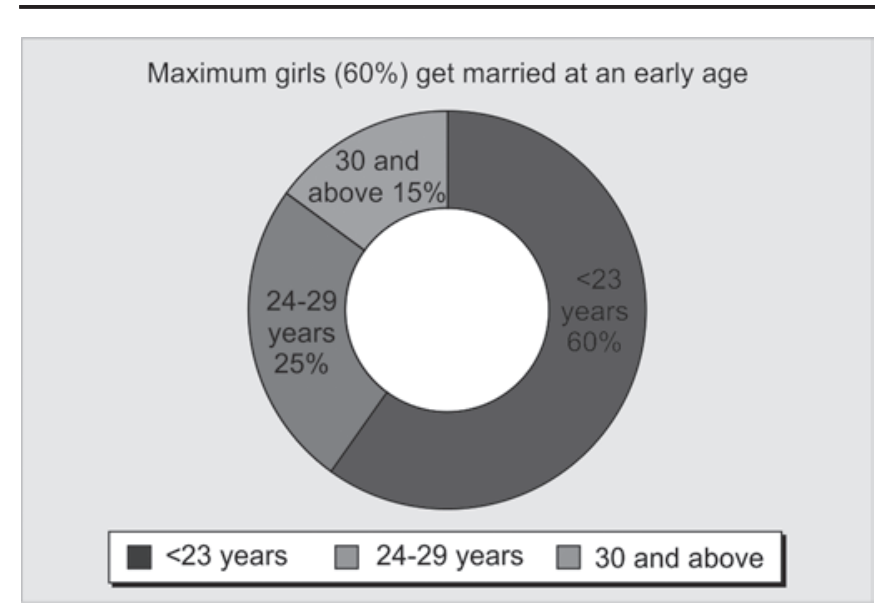

Fig. 7: Age of consummation of marriage

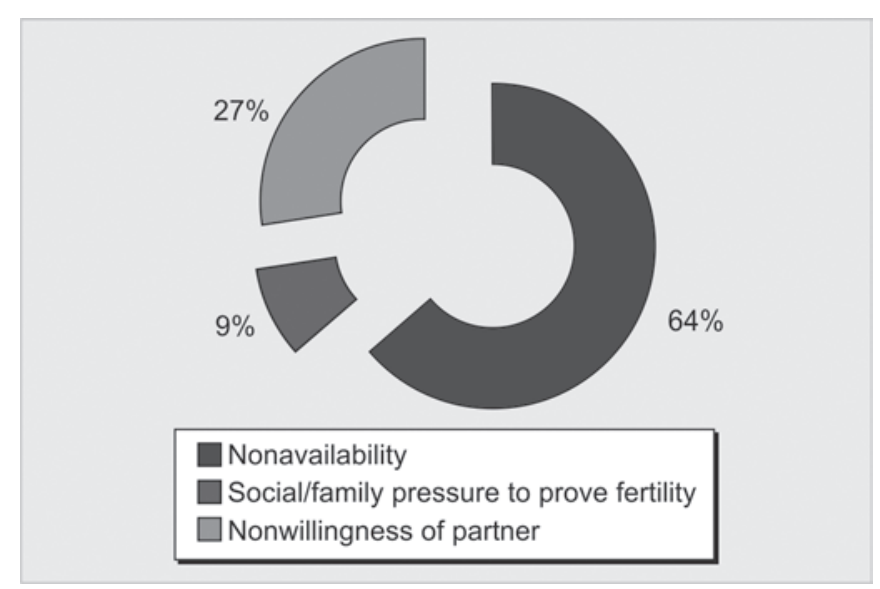

Fig. 8: Reasons cited for nonuse of contraception

\section{CONCLUSION}

- A large gap between knowledge and practice is seen despite good awareness about contraception.

- Permanent method of contraception mainly tubectomy, accounts for around $50 \%$ contraceptive use, similar to NFHS III study.

- Tubectomy along with MTP is the most frequent contraception in present study.

- Most have adopted this method only after adding a large burden to the population and with present existing pregnancy thereby defeating the purpose of family planning.

Lower literacy rate and poor availability of contraception are important factors for lower adoption rate in rural areas.

- The commonest reason quoted by the women for not using a contraceptive method was nonavailability and unwillingness of husband.

- The current unmet need is quite high, if this is met then the couple protection rate can increase considerably.

\section{REFERENCES}

1. Cleland J, Bernstein S, Ezeh A, Faundes A, Glasier A, Innis J. Family planning: The unfinished agenda. Lancet 2006;368: 1810-27.

2. United Nations Population Fund: State of the world population. The Cairo consensus at ten: Population, reproductive health and the global effort to end poverty, New York: UNFPA 2004.
3. World Health Organisation: Making Pregnancy Safer: Annual Report Geneva: World Health Organisation; 2008.

4. Baveja R, Buckshee K, Das K, et al. Evaluating contraceptive choice through the method-mix approach. An Indian Council of Medical Research (ICMR) Task Force Study. Contraception 2000;61:113-19.

5. Bongaarts J, Johansson E. Future trends in contraceptive prevalence and method mix in the developing world. Stud Fam Plann 2002;33:24-36.

6. Vlassoff, Singh MS, Darroch JE, Carbone E, Bernstein S. Assessing costs and benefits of sexual and reproductive health interventions. Occasional Report. New York: The Alan Guttmacher Institute 2004; 11.

7. Potts M, Fotso JC. Population growth and the millennium development goals. Lancet 2007;360:354-55.

8. Allen R. The role of family planning in poverty reduction. Obstetrics and Gynecology 2007;110:999-1002.

9. Walby S. Theorizing patriarchy. Cambridge, MA: Blackwell Publishers 1990.

10. Mitchinson W. The nature of their bodies: Women and their doctors in Victorian Canada Toronto. University of Toronto Press 1991:127.

11. Campbell M, Sahin-Hodoglugil NN, Potts M. Barriers to fertility regulation: A review of the literature. Stud Fam Plann 2006, 37:87-98.

12. Gage AJ. Sexual activity and contraceptive use: The components of the decision-making process. Stud Fam Plann 1998;29: $154-66$.

13. Women's Health Surveillance Report Published: 25 August 2004 BMC Women's Health 2004, 4(Suppl 1):S25 DOI: 10.1186/ 1472-6874-4-S1-S25 http://www.biomedcentral.com/1472$6874 / 4 / \mathrm{S} 1 / \mathrm{S} 25$.

14. Cibula D. Women's contraceptive practices and sexual behaviour in Europe. Eur J Contracept Reprod Health Care 2008; 13:362-75.

15. US Department of Health and Human Services. Centers for disease control and prevention. National Center for Health Statistics. Use of contraception in the United States: 1982-2008. Vital and Health Statistics Series 23, Number 29, May 2010.

16. Richters J, Grulich AE, De Visser RO, et al. Contraceptive practices among a representative sample of women. Aust NZ J Public Health 2003;27:210-76.

\section{ABOUT THE AUTHORS}

\section{Amrita Sinha}

Senior Resident, Department of Obstetrics and Gynecology JN Medical College and AVBR Hospital, Wardha, Maharashtra, India

\section{Neharika Malhotra}

Senior Resident, Department of Obstetrics and Gynecology JN Medical College and AVBR Hospital, Wardha, Maharashtra, India

\section{SA Inamdar}

Professor and Head, Department of Obstetrics and Gynecology JN Medical College and AVBR Hospital, Wardha, Maharashtra, India

\section{CORRESPONDING AUTHOR}

Neharika Malhotra, Senior Resident, Department of Obstetrics and Gynecology, 84 MG Road, Malhotra Nursing Home, Agra-282010 Uttar Pradesh, India, e-mail: dr.neharika@gmail.com 